\title{
IMPLEMENTASI MEDIA ONLINE (WEBSITE) SEBAGAI PUBLIKASI POTENSI DESA SIDODADI MELALUI PEMBERDAYAAN KARANG TARUNA
}

\author{
Moh Ahsan, Abdul Aziz \\ Fakultas Teknik Informatika Universitas Kanjuruhan Malang \\ ahsan@unikama.ac.id.
}

\begin{abstract}
Sidodadi Village is one of the villages located in southern Malang area located in Gedangan sub-district. The village is one of the villages that has the most extraordinary natural potentials such as Ungapan Beach, Bajulmati Beach, Parangdowo Beach, Jolangkung Beach, Bengkung Beach, Ngudel Beach, and Ngantep Beach, which is a beach located in the southern cross of Malang Regency. Rows of mountains are sturdy and beautiful to make the tourists interested to travel there. Sidodadi village area bounded with Sumbermanjing wetan district in the east, village elephant rejo in the west. On the other hand, not only the potential of nature is extraordinary, but the results of the abundant earth. Rice, corn, coconut, banana, rice, cassava, mangosteen, durian, and palm are natural products that can be processed there. The potential possessed and remarkable until now has not been published or promoted through websites and social media, to hog the visitors who more aplagi most visitors see the first reference before coming directly. The abundant natural resources with the stammered human resources of technology will make the potential of nature unknown to the wider community. Coral cadets and devices in the village of Sidodadi maximal educated High School (SMA) and only two people who can take the bench lecture. This is where the turmoil experienced by villagers Sidodadi where they can not publish the area. Only limited to the beaches that have been published, but for other natural potentials can not be published because of lack of knowledge about the use of the internet (Online Media).
\end{abstract}

Keywords: Sidodadi, Karangtaruna, Publikasi, Online.

\begin{abstract}
Abstrak
Desa Sidodadi merupakan salah satu desa yang berada di wilayah Malang bagian selatan yang terletak di Kecamatan Gedangan. Desa tersebut merupakan salah satu desa yang memiliki potensi alam yang sangat luar biasa seperti Pantai Ungapan, Pantai Bajulmati, Pantai Parangdowo, Pantai Jolangkung, Pantai Bengkung, Pantai Ngudel, dan Pantai Ngantep, yang merupakan pantai yang berada di lintas selatan kabupaten Malang. Deretan gunung-gunung yang kokoh dan indah membuat para wisatawan tertarik untuk berwisata disana. Wilayah desa Sidodadi berbatas dengan Kecamatan Sumbermanjing Wetan di sebelah timur, desa Gajah Rejo di sebelah barat. Disisi lain bukan hanya potensi alamnya saja yang luar biasa, namun hasil buminya melimpah ruah. Padi, jagung, kelapa, pisang, padi, ketela pohon, manggis, duren, dan sawit merupakan hasil alam yang dapat diolah disana. Potensi yang dimiliki dan luar biasa itu sampai saat ini belum dipublikasikan atau dipromosikan melaui website dan media sosial, untuk mendomprak pengunjung yang lebih banyak apalagi kebanyakan pengunjung melihat referensi terlebih dahulu sebelum datang langsung. Sumber daya alam yang melimpah ruah dengan sumber daya manusia yang gagap akan teknologi akan membuat potensi alam tidak dikenal oleh masyarakat luas. Karang taruna dan perangkat di Desa Sidodadi maksimal berpendidikan Sekolah Menengah Atas (SMA) dan hanya 2 orang saja yang dapat menempuh bangku perkuliahan. Disinilah kegalauan yang dialami oleh masyarakat desa Sidodadi dimana mereka belum bisa mempublikasikan daerahnya. Hanya sebatas Pantainya saja yang sudah terpublikasikan, namun untuk potensi alam lainnya belum dapat terpublikasikan karena minimnya pengetahuan tentang manfaatan internet (Media Online).
\end{abstract}

Kata Kunci: Desa Sidodadi, Karangtaruna, Publikasi, Online.

36| MARTABE : Jurnal Pengabdian Masyarakat 


\section{PENDAHULUAN}

Internet merupakan salah satu media komunikasi, transaksi, mencari referensi/ilmu, hingga melakukan sebuah kejahatan. Mengakses internet dapat dilakukan dimana saja dengan syarat ada jaringan internet dan penggunaan internet dapat dilakukan oleh siapa saja dan kapan saja dari semua kalangan mulai dari yang ekonomi tingkat atas hingga tingkat bawah, namun kendalanya adalah apakah jaringan internet sudah terjangkau untuk diakses ditempat, terutama di pedesaan dan daerah pelosok. Tidak heran ketika ada anak usia 2 tahun sudah mampu menggunakan media internet untuk memainkan sebuah game online yang sekarang marak dan digemari oleh kaum muda. Begitu pesat dan meningkatnya pengguna internet sehingga dapat digunakan dalam hal yang manfaat.

Sudah dijelaskan diatas bahwa internet sebagai media komunikasi yang sering disebut medsos (Media Sosial) yang dapat melakukan komunikasi dan transaksi seperti Facebook, Instagram, BBM, WA (Whatsaap), Line, dll. Menurut Wikipedia, media sosial adalah sebuah media online, dengan para penggunanya (users) bisa dengan mudah berpartisipasi, berbagi, dan menciptakan isi meliputi blog, jejaring sosial, wiki, forum, dan dunia virtual. Blog, jejaring sosial dan wiki merupakan bentuk media sosial yang paling umum digunakan oleh masyarakat di seluruh dunia. Andreas Kaplan dan Michael Haenlein mendefinisikan media sosial sebagai "sebuah kelompok aplikasi berbasis internet yang membangun di atas dasar ideologi dan teknologi Web 2.0, dan yang memungkinkan penciptaan dan pertukaran user-generated content" (Kaplan, Andreas M.; Michael Haenlein [2010] "Users of the world, unite! The challenges and opportunities of Social Media". Business Horizons. ${ }^{1]}$

Desa yang memiliki jumlah penduduk sebanyak 7000 juta jiwa ini mayoritas bekerja sebagai petani. Hampir $75 \%$ penduduk usia produktif menjadi petani, sisanya menjadi guru, pedagang, buruh, dan nelayan. Wilayah desa Sidodadi berbatas dengan kecamatan Sumbermanjing Wetan di sebelah timur, Desa Gajah Rejo di sebelah barat. Disisi lain bukan hanya potensi alamnya saja yang luar biasa, namun hasil buminya melimpah ruah. Padi, jagung, kelapa, pisang, padi, ketela pohon, manggis, duren, dan sawit merupakan hasil alam yang dapat diolah disana. Potensi yang dimiliki dan luar biasa itu sampai saat ini belum dipublikasikan atau dipromosikan melaui website dan media sosial, untuk mendomprak pengunjung yang lebih banyak aplagi kebanyak pengunjung melihat refersensi terlebih dahulu sebelum datang langsung.

Sumber daya alam yang melimpah ruah dengan sumber daya manusia yang GAPTEK akan teknologi akan membuat potensi alam tak terdikenal oleh masyarakat luas. Karang taruna dan perangkat di desa sidodadi maksimal berpendidikan Sekolah Menengah Atas (SMA) dan hanya 2 orang saja yang dapat menempuh bangku perkuliahanan. Disinilah kegalauan yang dialami oleh masyarakat desa sidodadi dimana mereka belum bisa mempublikasikan daerahnya. Hanya sebatas Pantainya saja yang sudah terpublikasikan, namun untuk potensi alam lainnya belum dapat terpublikasikan karena minimnya pengetahuan tentang pemanfaatan internet. 
Moh Ahsan, dkk. Implementasi Media Online (Website) Sebagai...

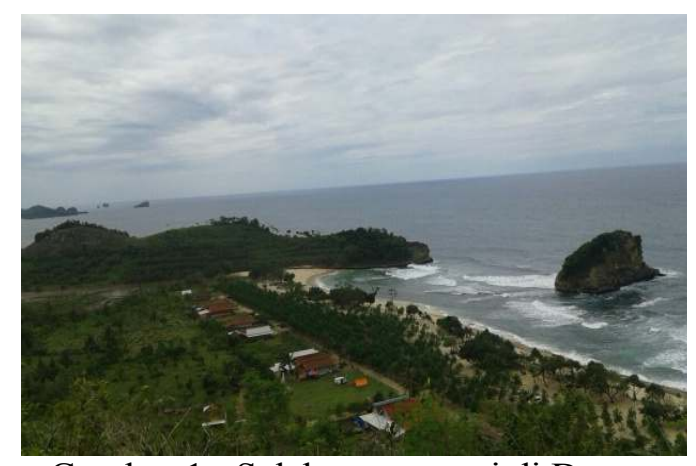

Gambar 1: Salah satu pantai di Desa Sidodadi

Desa yang memiliki jumlah penduduk sebanyak 7000 juta jiwa ini mayoritas bekerja sebagai petani. Hampir $75 \%$ penduduk usia produktif menjadi petani, sisanya menjadi guru, pedagang, buruh, dan nelayan. Wilayah desa Sidodadi berbatas dengan kecamatan Sumbermanjing Wetan di sebelah timur, Desa Gajah Rejo disebelah barat (http://kependudukan. lipi.go.id/id/kajian-kependudukan/desakota/91-derita-petani-indonesi). Disisi lain bukan hanya potensi alamnya saja yang luar biasa, namun hasil buminya melimpah ruah. Padi, jagung, kelapa, pisang, padi, ketela pohon, manggis, duren, dan sawit merupakan hasil alam yang dapat diolah disana. Potensi yang dimiliki dan luar biasa itu sampai saat ini belum dipublikasikan atau dipromosikan melaui website dan media sosial, untuk mendomprak pengunjung yang lebih banyak aplagi kebanyak pengunjung melihat refersensi terlebih dahulu sebelum datang langsung.

\section{METODE PELAKSANAAN}

Metode pelaksanaan yang dilaksanakan dalam pengabdian adalah untuk memenuhi target pengembangan potensi desa melalui pembuatan website yang dilakukan dalam beberapa proses, sebagai berikut:

(1)Pengabdian kepada masyarakat dilakukan dengan melalui observasi lapangan terlebih dahulu untuk melihat bagaimana keadaan penduduk desa sidodadi dan bagaimana pitensi alam yang dilaksanakan pada tanggal 5 dan tanggal 6 agustus pada hari sabtu dan minggu.

(2)Melakukan MoU dengan pihak desa dan juga pihak karang taruna untuk memastikan apakah kegiatan pengabdian bersifat legal, dilakukan dibalai desa sidodadi kecamatan gedangan.

(3)Penyaringan dan pengelompokan potensi yang telah dimiliki desa sidodadi kecamatan gedangan kabupaten Malang dengan bertanya langsung kepada tokoh masyarakat, pemuda karang taruna dan penduduk di desa sidodadi.

(4)Memberikan materi tentang pemahaman internet dan sosial media kepada karang taruna.

(5)Pelaksanaan pendampingan pembuatan Website desa dengan mengisi konten potensi alam Desa Sidodadi Kecamatan Gedangan. pendampingan diisi oleh pengabdi sendiri yang dibantu oleh salah satu mahasiswa Universitas Kanjuruhan Malang. Setelah dilaksanakan kegiatan pendampingan dilanjutkan dengan melakukan pendampingan untuk setiap bulannya, agar tetap terpantau bagaimana perkembangan website yang telah dikelola.

\section{HASIL DAN PEMBAHASAN}

Hasil yang dicapai yang pertama adalah Melakukan observasi lapangan bersama dengan satu mahasiswa Universitas Kanjuruahan Malang dan salah satu warga Desa Sidodadi Kecamatan Gedangan Kabupaten Malang yang dilaksanakan pada hari sabtu dan minggu, pada tanggal 5 dan 6 
agustus 2017. Setelah melakukan observasi dilapangan ternyata Malang mempunyai banyak potensi wisata pantai terutama dimalang selatan, Selain dikenal sebagai kota wisata di Jawa Timur, ternyata Malang memiliki banyak tempat wisata Pantai yang eksotis, menakjubkan dan memanjakan pengunjung.

Sebagian besar wilayahnya merupakan pegunungan yang berhawa sejuk, Kabupaten Malang dikenal sebagai salah satu daerah tujuan wisata utama di Jawa Timur. Bersama dengan Kota Batu dan Kota Malang, Kabupaten Malang merupakan bagian dari kesatuan wilayah yang dikenal dengan Malang Raya. Meskipun malang sebagian besar wilayah berupa pegunungan, namun malang juga banyak tersedia tempat wisata pantai dan bisa dibilang Malang merupakan salah satu surganya. Banyak sekali pantai-pantai di Malang yang masih belum terekpost luas keberadaannya yang bisa anda jelajahi untuk menghabiskan liburan. Dari pada penasaran, berikut pantai di Malang yang bisa dijelajahi, karena ini bukan pantai yang sudah biasa dikunjungi para wisatawan karena letaknya tersembunyi.

Pantai merupakan wisata favorit bagi semua kalangan dan sangat cocok dikunjungi bagi Wisatawan yang ingin berlibur bersama keluarga, Sahabat ataupun Rekan Kantor, Berwisata di Pantai juga bisa memberikan sensasi berlibur yang berbeda dan Menyenangkan. Selain wisata di Pantai banyak disukai, Pengunjung bisa bermain air, Berenang maupun hanya sekedar berfoto. Berfoto dengan latar belakang laut memberikan kesenangan tersendiri dan Pastinya Selain bermain di Pantai, bahkan pengunjung bisa mencicipi kuliner seafood yang sangat dinantikan saat berwisata di Pantai. Berikut ini sederatan pantai yang ada di Desa Sidodadi Dolan-doalan [Internet]. [cited 10 Agustus 2017].

Tabel 1: Deretan Pantai yang ada di Desa Sidodadi, Kecamatan Gedangan

(Wisatalengkap [Internet]. [cited 10 Agustus 2017]

\begin{tabular}{ll}
\hline \multicolumn{1}{c}{ Nama Pantai } & \multicolumn{1}{c}{ Keterangan } \\
\hline Pantai Ungapan & $\begin{array}{l}\text { Jarak dari Kota Malang sekitar 75 KM dan waktu tempuh sekitar 3 } \\
\text { jam perjalanan. }\end{array}$ \\
Pantai Bajul Mati & Jarak 58 KM ke arah selatan dari kota Malang \\
Pantai Parang Dowo & Akses ke pantai Parang Dowo harus mengunakan kendaraan pribadi \\
& karena angkutan umum masih belum \\
Pantai Jolangkung & $\begin{array}{l}\text { Pantai yang banyak tanjakan yang cukup curam dengan kemiringan } \\
\text { sekitar 70 derajat dan melewati hutan }\end{array}$ \\
Pantai Bengkung & $\begin{array}{l}\text { Pantai Bengkung merupakan salah satu destinasi wisata pantai yang } \\
\text { terletak di pesisir jalur Lintas Selatan }\end{array}$ \\
Pantai Ngudel & Jarak sekitar 60 Meter dari Malang ke Pantai Ngudel terletak di \\
& sebelah barat Pantai Kletekan dan Pantai \\
Pantai Ngantep & $\begin{array}{l}\text { Pantai Ngantep terletak di Dusun Sukorejo, Desa Tumpakrejo, } \\
\text { Kecamatan Gedangan, Kabupaten Malang }\end{array}$ \\
\hline
\end{tabular}


Moh Ahsan, dkk. Implementasi Media Online (Website) Sebagai...

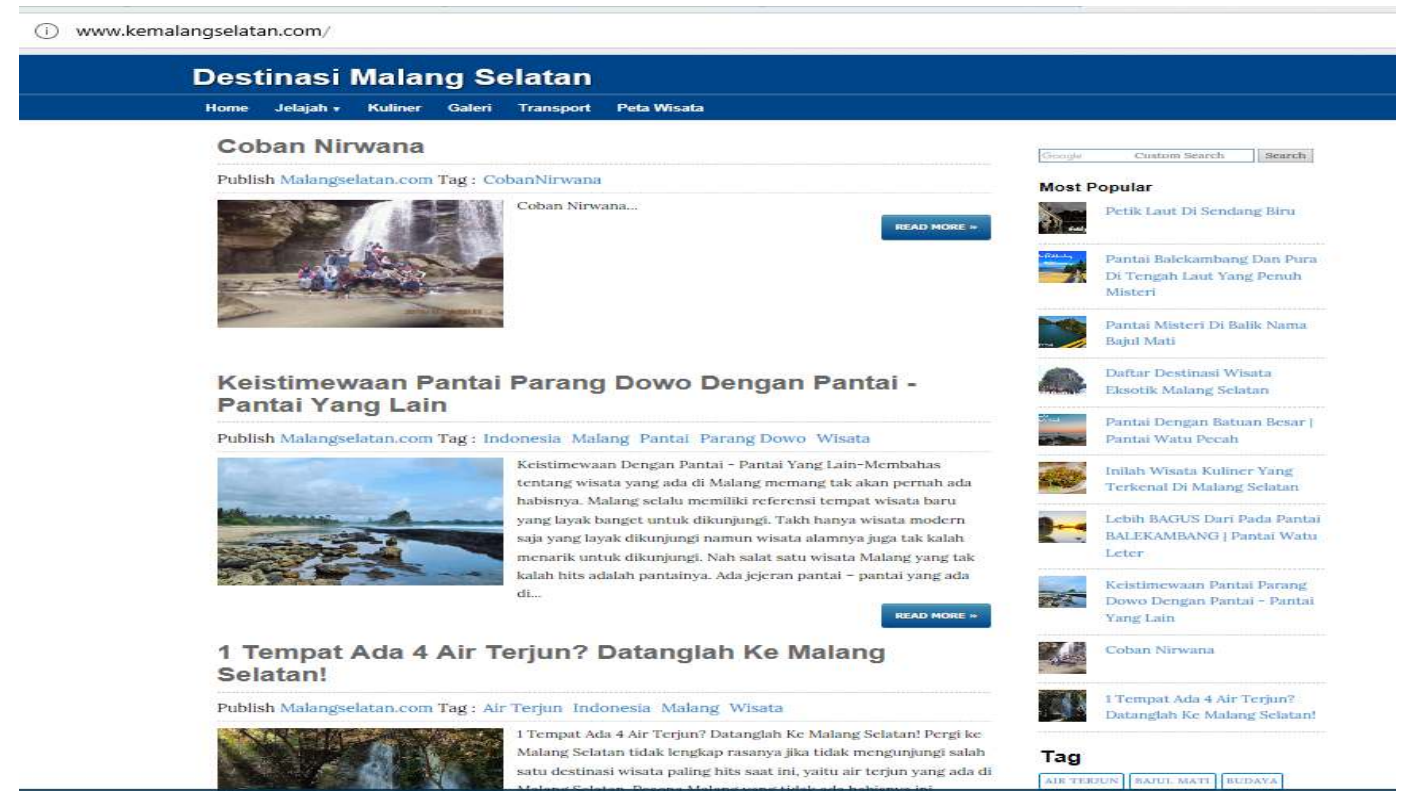

Gambar 2: Website Destinasi Malang Selatan

Hasil yang dicapai kedua adalah telah melakukan pendampingan kepada pemuda karangtaruna dilaksanakan dibalai Desa Sidodadi Kecamatan Gedangan Kabupaten Malang dengan peserta 15 orang, maksimal pendidikan yang ikut dalam pendampingan sudah lulus SMA (Sekolah Menengah Atas) bahkan bapak kepala desa pun ikut andil dalam Pendampingan "Membuat Media Online (Website: www.kemalangselatan. com) Sebagai Sarana Publikasi Potensi Desa Sidodadi Melalui Pemberdayaan Karang Taruna".

Kegiatan pengabdian dilakukan oleh ketua tim (Moh. Ahsan), anggota tim (Abdul Aziz), dan Mahasiswa teknik Informatika. Kegiatan dibagi menjadi dua tahap yang meliputi: 1). Pendampingan dan Transfer ilmu tentang internet dan website dalam promosi potensi desa dengan tujuan agar dapat menggunakan media online berjalan dengan lancar. Pendampingan penggunaan media online akan dilaksanakan dengan peserta dari perangkat desa dan pemuda karang taruna sehingga bias mengisi berita dikonten website yang akan dibuat. Tenaga Ahli: Moh. Ahsan, S.Kom, MT. 2).
Pendampingan dalam memaksimalan hasil produk dan kegiatan pemuda karangtaruna dengan cara memanfaatkan website untuk mengisi konten website dan untuk meningkatkan produktivitas serta kretifitas pemuda karangtaruna dalam memasarkan potensi desa, agar konten dan isi website dapat menarik dan selalu update dengan berita terbaru. Tenaga Ahli: Abdul Aziz, M. Kom. Kegiatan selanjutnya adalah Pendampingan yang akan dilakukan selama satu tahun dengan selalu mematau selama perbulan.

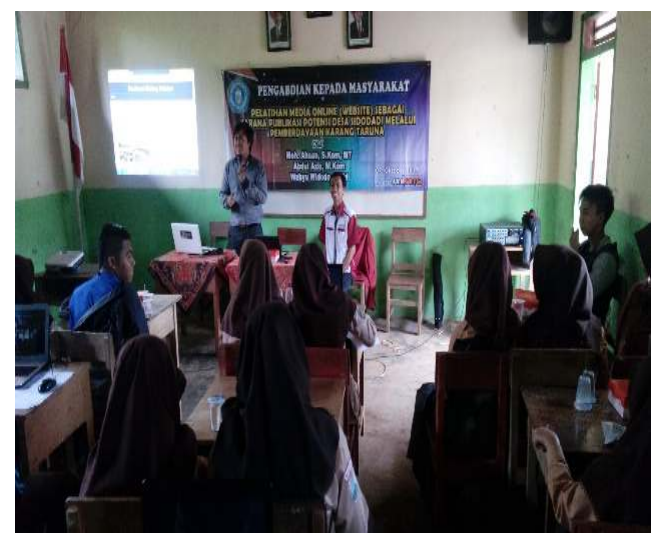

Gambar 3: Pendampingan dan Pelaksanaan Pengabdian 


\section{SIMPULAN}

\begin{abstract}
Kegiatan Pendampingan dalam Membuat Media Online (Website) bertujuan untuk Sarana Publikasi Potensi Desa Sidodadi Melalui Pemberdayaan Karang Taruna yang telah dilakukan mendapat dukungan dan respon yang positif serta merupakan harapan kepala desa untuk mempromosikan potensi desa di dunia nasional bahakan internasional. Transfer ilmu bagi pemuda karangtaruna menjadi hal yang baru karena Pendampingan dalam membuat media online terutama dalam pembuatan website sudah menjadi kewajiban diera digital. Harapan dalam kegiatan ini tidak putus sampai pada Pendampingan saja namun kontroling dan bimbingan tetap diinginkan.
\end{abstract}

\section{UCAPAN TERIMA KASIH}

Terima Kasih kepada LPPM Universitas Kanjuruan Malang yang telah mensupport demi susksesnya pengabdian Sesuai dengan Surat Perjanjian Nomor: 076/C3/I.3/LPPMUK/2016 dan pihak terkait di Desa Sidodadi.

\section{DAFTAR PUSTAKA}

Andreas M. Kaplan*, Michael Haenlein, Business Horizons (2010). Users of the world, unite! The challenges and opportunities of Social Media ESCP Europe, 79 Avenue de la Re 'publique, F-75011 Paris, France. 53, 59-68.Eugene F. Brigham, Manajemen Keuangan, Buku I, Edisi Kedelapan, Penerbit Erlangga diakses tgl 2 Agustus 2017.

Dolan-doalan [Internet]. [cited 10 Agustus 2017]. Available from: https://dolandolen.com/traveldirectory/pantai-ngantep/

Wisatalengkap [Internet]. [cited 10 Agustus 2017]. Available from https://wisatalengkap.com/temp at-wisata-pantai-malang-bagusdan-mudah-dijangkau/

http://kependudukan.lipi.go.id/id/kajian -kependudukan/desa-kota/91derita-petani-indonesi 